\title{
CURRÍCULO E QUESTÕES DE GÊNERO UMA RELAÇÃO DE PODER EM MEIO ESCOLAR
}

\author{
CURRÍCULO Y CUESTIONES DE GÉNERO \\ UNA RELACIÓN DE PODER EN MEDIO ESCOLAR
}

CURRICULUM AND GENDER ISSUES

A RELATIONSHIP OF POWER IN SCHOOL

\author{
Cristiane de Assis LUCIFORA ${ }^{1}$ \\ Fábio Tadeu REINA ${ }^{2}$
}

RESUMO: Este artigo traz reflexões relacionadas aos mecanismos de poder presentes nas práticas escolares e o alcance ideológico em transmitir conteúdos excludentes como, por exemplo, as constituições de gênero. Pensa-se o poder na seleção de determinados conteúdos vistos como importantes e necessários e a razão de alguns conteúdos não serem considerados relevantes no processo de ensino e aprendizagem. Pensa-se a esfera do discurso na perspectiva de a escola atuar como espaço democrático, buscando a equidade, porém acaba por sancionar as desigualdades originárias pela situação social dos agentes. A Educação Sexual coloca-se como tabu social, não encontrando campo favorável para sua adoção pela escola, ganhando muitas vezes um espaço velado no qual os professores colaboram para a reprodução do silêncio.

PALAVRAS-CHAVE: Currículo. Poder. Desigualdade. Educação sexual.

RESUMEN: Este artículo trae reflexiones relacionadas a los mecanismos de poder presentes en las prácticas escolares y el alcance ideológico en transmitir contenidos excluyentes como, por ejemplo, las constituciones de género. Se piensa el poder en la selección de determinados contenidos vistos como importantes y necesarios y la razón de que algunos contenidos no sean considerados relevantes en el proceso de enseñanza y aprendizaje. Se piensa la esfera del discurso en la perspectiva de que la escuela actúe como espacio democrático, buscando la equidad, pero acaba por sancionar las desigualdades originarias por la situación social de los agentes. La Educación Sexual se sitúa como tabú social, no encontrando campo favorable para su adopción por la escuela, ganando muchas veces un espacio velado en el que los profesores colaboran para la reproducción del silencio.

PALABRAS CLAVE: Currículo. El poder. Desigualdad. Educación sexual.

${ }^{1}$ Universidade Estadual Paulista (UNESP), Araraquara - SP - Brasil. Professora de Educação Infantil na rede municipal de ensino da cidade de São Carlos/SP. Mestre em Educação Sexual. ORCID: <http://orcid.org/0000-0002-8937-6412>.E-mail: cristiane_pbf1@yahoo.com.br

2 Universidade de Araraquara (UNIARA), Araraquara - SP - Brasil. Docente. ORCID: <http://orcid.org/0000-0002-2591-2378>. E-mail: ftreina@ hotmail.com 
ABSTRACT: This article traces reflections related to the mechanisms of power present in the school practices and the ideological reach in transmitting contents that manifest excluding contents as for example the constitutions of gender. Power is thought in the selection of certain contents that are seen as important and necessary and why some contents are not dignified to be present in the process of teaching and learning. It is thought the sphere of discourse that the school acts as a democratic space and search for equity, but which actually sanctions the inequality originated by the social situation that the agents are. Sexual Education, often assumed as a social taboo, finds no positive field to be incorporated into school walls, often gaining a veiled space in which teachers collaborate to reproduce something worthy of silence.

KEYWORDS: Curriculum. Power. Inequality. Sexual education.

$\mathrm{O}$ artigo que se segue reflete sobre as teias de poder presentes na seleção, manifestação e relação do currículo, no que diz respeito à Educação Sexual no âmbito escolar. Trata-se de trazer à discussão o quanto ainda há de tabus por trás de questões relacionadas ao gênero e sexualidade, uma vez que os sujeitos responsáveis pelo ensino e aprendizagem serem construídos no seio da cultura e incorporarem as tramas sociais que delimitam o que é aceitável ou não.

Primeiramente, é necessário compreender currículo como poder manifesto tanto consciente quanto inconsciente, colocado em prática dentro dos conteúdos ensinados, nas diversas relações empreendidas entre os sujeitos, nos ritos presentes na instituição escolar, na divisão dos espaços, etc.

Compreender que a escola, apesar de um discurso assumidamente de neutralidade e democracia, é envolta por dispositivos que consagram a desigualdade social faz-se extremamente importante. É necessário descortinar a ideia de que a escola é um espaço neutro e compreender através de quais meios ela propaga a desigualdade.

Os usos que se faz do currículo na instituição, assim como sua finalidade e seleção precisam ser repensados, além da compreensão da necessidade de um dado conteúdo, seu objetivo e como se dá a relação do sujeito, para o qual o ensino é voltado, no processo de ensino-aprendizagem. A instituição escolar tem sua marca histórica consagrada por uma forte doutrinação infantil e sua subordinação, assim como a ideia de que as crianças não possuem a criticidade para compreender determinados conteúdos.

A teoria crítica, assim como a pós-crítica, traz o questionamento no que diz respeito ao currículo, aos interesses e às relações de poder, o que leva um determinado conhecimento ser considerado de mais valor que outro e o que motiva a seleção de 
alguns conteúdos escolares sejam incorporados, enquanto outros são deixados de lado. Tais teorias demonstram que o currículo está intimamente ligado a estruturas de poder complexas presentes na sociedade, sendo a escola um lócus de propagação destas estruturas.

Como aponta (DA SILVA, 2005, p. 16) "Selecionar é uma operação de poder. Privilegiar um tipo de conhecimento é uma operação de poder. Destacar, entre as múltiplas possibilidades, uma identidade ou subjetividade como sendo a ideal é uma operação de poder".

Coloca-se assim uma preocupação para o entrelaçamento entre saber, identidade e poder. Ao questionarmos sobre o que é assumido na escola como currículo necessário, entendemos como essa seleção acaba voltando-se para os interesses de uma dada população no qual o conhecimento soa natural e sem transtornos para ser incorporado.

Historicamente, a ampliação de acesso à escolarização básica, motivada por luta política e social no Brasil, não veio acompanhada de um acesso igualitário, já que o conhecimento inserido na escola para alguns acontece de forma natural e bem próxima do meio de convívio. Já para outros, há um verdadeiro abismo no que se refere a isso.

Apple (1995) aponta que a decisão de se definir o conhecimento de um grupo como mais digno de ser transmitido na escola exclui a história e cultura de outros grupos e revela quem detém o poder na sociedade. $\mathrm{O}$ conhecimento selecionado pode assim ser visto pela dimensão de poder que oculta e que intensifica a ideia de que um conhecimento é mais valioso que outro.

Segundo Cambi (1999, p. 513):

No século XX, a escola sofre processos de profunda e radical transformação. Abre-se às massas. Nutre-se de ideologia. Afirma-se cada vez mais central na sociedade (para ofuscar essa centralidade só por volta do fim do século, na época do mass media). Essa renovação foi maior no âmbito da tradição ativista, quando a escola se impôs como instituição-chave da sociedade democrática e se nutriu de um forte ideal libertário.

Para tal autor, apesar de transformar-se, deslocando a criança para o centro, de forma que suas necessidades e capacidades tenham destaque, a escola continua a ser pensada na modernidade por diversas perspectivas, trazendo a necessidade de reconhecimento de seu grau de influência e como os agentes escolares levam para a instituição a formação de suas identidades. Cabe reconhecer que tais agentes envolvidos 
têm suas marcas de vida pautadas em suas vivências particulares e estas refletem nas relações entre esses e claramente no que é transmitido.

Segundo Candau (2008, p. 33):

A escola como instituição está construída tendo por base a afirmação de conhecimentos considerados universais, uma universalidade muitas vezes formal que, se aprofundarmos um pouco, termina por estar assentada na cultura ocidental e europeia, considerada como portadora da universalidade.

O currículo selecionado para o acesso ao conhecimento está envolvido por uma rede de poder complexa, que por se colocar tão sutil na sua ação diária, ensina conteúdos bem como atitudes, formas de ser, estar e agir.

A prática curricular segue por duas direções: uma voltada para ação consciente com seleção direta de conteúdos com um dado propósito de ensino e outra vista pela dimensão oculta, que é responsável por aquilo que se desenrola na trama escolar, presente nas relações de todos os tipos com os diferentes sujeitos. A atividade docente encontra-se repleta de ideais estruturadores de suas identidades que se manifestam no desenrolar da ação prática docente.

Segundo Nogueira (2010, p. 37), “A autoridade alcançada por uma ação pedagógica, ou seja, a legitimidade conferida a essa ação e aos conteúdos que ela distribui seriam proporcionais à sua capacidade de se apresentar como não arbitrária e não vinculada a nenhuma classe social".

A ação curricular durante muito tempo foi assumida como seleção de conteúdos de forma linear, sem considerar o contexto social no qual é colocada em prática; as relações entre os sujeitos, que são o foco da aprendizagem, não eram tomadas em sua complexidade. Essas relações travadas no seio escolar denominam-se como currículo oculto, porque não se coloca como uma realidade prevista e na maioria das vezes não identificada; tal currículo pode ser considerado como as características presentes na instituição, sem fazer parte do currículo oficial e explícito, que influenciam grandemente as aprendizagens tomadas como relevantes na sociedade.

É necessário compreender o currículo não só em sua dimensão instrumental, mas também em seus aspectos ocultos, já que os conhecimentos valorizados no processo de escolarização são tidos como conhecimentos necessários e que a necessidade se faz para todos de forma igual, sem pensar e integrar a diferença de forma concreta em toda dimensão curricular apontando para a superação das desigualdades sociais. 
A sociedade e a cultura devem ser pensadas em sua dimensão meritocrática, descortinando a ideologia de neutralidade sobre a escola. A instituição escolar não é um campo neutro e está repleta de transmissões de juízos de valores inclusive no que diz respeito as imagens de gênero.

Como aponta Nogueira (2010, p. 37):

Uma vez reconhecida como legítima, ou seja, como portadora de um discurso universal (não arbitrário) e socialmente neutro, a escola, na perspectiva bourdieusiana, passa a exercer, livre de qualquer suspeita, suas funções de reprodução e legitimação das desigualdades sociais.

Levando em conta a história do currículo, pode-se perceber que sua complexidade, dentre outras coisas, sua fragmentação, segmentação e seleção começa a firmar-se historicamente diante da intensa massificação da instituição escolar. Durante muito tempo, o estudo do currículo ficou limitado a aspectos instrumentais e técnicos, como se este seguisse uma lógica de neutralidade e desvinculado dos embates travados no seio da sociedade.

Para Apple (1995, p. 39):

Não se trata 'apenas' de uma questão educacional, mas de uma questão intrinsecamente ideológica e política. Quer reconheçamos ou não, o currículo e as questões educacionais mais genéricas sempre estiveram atrelados à história dos conflitos de classe, raça, sexo e religião $[\ldots]$

Da Silva (2005) traz a importante questão da cultura popular ao incorporar as contribuições de Henry Giroux nos estudos sobre currículo e também por mostrar a perspectiva da possibilidade de resistência no processo de possível transformação social; a superação do pessimismo e imobilismo são incorporados e tidos como necessários. (DA SILVA, 2005, p. 54) aponta que "É através de um processo pedagógico que permita às pessoas se tornar conscientes do papel de controle e poder exercido pelas instituições e pelas estruturas sociais que elas podem se tornar emancipadas ou libertadas de seu poder e controle".

Trazendo a questão multicultural, Da Silva (2005) afirma que a diferença não pode ser vista como algo que deva ser tolerado ou respeitado, mas como uma questão permanente, expandindo o leque da compreensão dos mecanismos, que geram as desigualdades nos marcadores sociais da diferença.

Podemos afirmar, por meio da problematização de Sacristán (2013), sobre a construção do currículo em toda a sua complexidade, que este atende a interesses 
externos à instituição escolar e que as marcas encontradas em todos os rituais empreendidos na escola, são marcas que delimitam o que se espera que os estudantes aprendam. A submissão, dominação e subordinação são estimuladas, assim sendo a escola age no sentido de reforçá-la sempre.

Compreende-se assim que o currículo não é uma realidade abstrata e neutra, mas sim uma práxis, sendo repleto de valores e conflitos e regado à relações de poder; para pensá-lo temos de considerar tanto os aspectos técnicos/instrumentais quanto as relações estabelecidads no âmbito escolar, repletas de mecanismos seletivos e excludentes.

Segundo Apple (2001, p. 53):

O currículo nunca é simplesmente uma montagem neutra de conhecimentos, que de alguma forma aparece nos livros e nas salas de aula de um país. Sempre parte de uma tradição seletiva, da seleção feita por alguém, da visão que algum grupo tem do que seja o conhecimento legítimo.

Em sua construção o currículo passa por julgamentos de valores, não se dando de forma neutra e desvinculada das relações complexas e forjadas no seio da sociedade. As relações são atravessadas por mecanismos de poder, portanto, a construção do currículo não poderia se dar de forma diferente.

Louro (1997) aponta a importância de questionar em um primeiro momento o que é visto como natural e transmitido de forma sutil no interior escolar (os currículos, normas, procedimentos, teorias, linguagem, material didático e processos de avaliação) e problematizar desta forma o que tem sido ensinado pela escola. Questionar um currículo como natural ou imutável deve ser um compromisso de todo educador, deve ser um compromisso a ser assumido no sentido da luta por transformação social.

A escola atua no sentido de fixar as formas de ser, estar e agir nos estudantes, enquadrando e delimitando o que deve ser considerado normal, seguindo a lógica do que se espera, enquanto carga cultural circunscrita na sociedade como um todo. Para tanto ela se utiliza de um leque de artefatos seja materiais/concretos ou psicológicos de inculcação de valores. Ainda nos dias de hoje, a instituição escolar é a responsável pela conformação nos estudantes do que se espera que eles desempenhem enquanto adultos.

Apple (2001, p. 68):

O currículo, então, não pode ser apresentado como 'objetivo'. Em vez disto, ele deve constantemente subjetivar a si próprio. Isto é, ele deve 
'reconhecer suas próprias raízes' na cultura, na história e nos interesses sociais a partir dos quais ele surge. Da mesma forma, ele não homogeneizará nem essa cultura, essa história e esse interesse social, nem os alunos. O 'mesmo tratamento', conforme o sexo, a raça, a etnia ou a classe, não é absolutamente o mesmo. Um currículo e uma pedagogia democráticos devem começar com o reconhecimento dos 'diferentes posicionamentos sociais e repertórios culturais nas salas de aula, e das relações de poder entre eles.

Diante desta situação, como afirma (MCLAREN, 1997, p. 35) "Mas parece que as condições deste presente momento conferem certa urgência a esta luta entre as pessoas que trabalham na educação". Os profissionais da educação têm um importante papel neste contexto de supremacia do capital, que rejeita relações humanas mais igualitárias - no sentido de direitos iguais para todos, inclusive de ser diferente -, para a construção de uma sociedade mais justa e desvinculada de preconceitos que estigmatizam, inferiorizam, oprimem e condicionam diversos grupos a seguirem uma lógica esperada para eles.

Os preconceitos e discriminações presentes nas relações sociais precisam caminhar para estratégias de desconstrução, de forma que qualquer tipo de naturalização seja questionada e superada e formas mais igualitárias, no sentido de que a difusão do conceito de direitos iguais para todos sem homogeneização se fortaleça.

Devemos resistir à imposição do modelo estereotípico e eurocêntrico: branco, homem, cristão, classe média, jovem, fisicamente capacitado e heterossexual, que tenta suprimir com que os que destoam deste padrão, considerando-os inferiores. Um dos caminhos possíveis é buscar compreender as raízes históricas e culturais que marcam a construção do considerado diverso e normal.

Os conhecimentos ideológicos devem ser repensados pelos profissionais da educação, de forma a reconhecer e, em seguida, desconstruir as tendências homogeneizadoras que impregnam, dentre outras coisas, o currículo em ação e as práticas escolares que são empregadas na instituição. A prática pedagógica precisa ser repensada para que se identifique as relações carregadas de valores ditos normais, necessários e importantes. Há de se refletir sobre os mecanismos de poder que perpassa cada atitude e dessa forma caminhar de forma individual, e por que não coletiva, na superação de tudo que tem atuado no sentido de marginalizar e oprimir.

Freitas (2002, p. 320):

A luta por uma escola para todos somente poderá ser consequente quando a escola for, além de um local de aprendizagem, um local de 
tomada de consciência e de luta contra as desigualdades sociais em estreita relação com os movimentos sociais emancipatórios, quando então a escola encontrará seu lugar formativo/instrutivo no nosso tempo.

A contestação e a desconstrução têm auxiliado na ruptura de alguns estigmas voltados para classe, gênero, etnia, sexualidade, entre outros. Na formação de futuros professores isso pode significar uma pedagogia voltada para a ressignificação, interrogação e desmistificação da sociedade, construindo um novo olhar, no qual a diversidade não é vista como um problema, mas como um caminho de potencialização para os indivíduos exercerem a dialogicidade.

Para Furlani (2011, p. 65)

Se considerarmos que a sexualidade (se referindo aqui a suas manifestações e seu desenvolvimento) é um componente humano e, portanto, um assunto de interesse infantil e jovem, então, da escola se espera uma atitude no sentido de garantir, em todos os níveis da escolarização brasileira, seu assumir pedagógico, possibilitando a sua discussão e inclusão curricular.

A sexualidade humana acompanha o desenvolvimento dos sujeitos não cabendo sua ocultação no currículo escolar, documentos como PCNs, DCNEI, RCNEI, assim como outros, preveem a incorporação dessa temátic na escola, mas envolvido nessas tramas complexas de poder, a sexualidade tem encontrado resistência e, na maioria das vezes, tem sido ignorado.

Devemos levar em conta que muitas mudanças ocorreram ao longo da história e que a educação não se coloca como acabada e estática, o que pode nos motivar e nos fazer acreditar que há possibilidade de superação dos mecanismos seletivo e excludente. Há movimentos sociais de resistência que vão contra as formas de opressão e exclusão e que tem auxiliado em uma visão crítica sobre a escola.

Como afirma (DA SILVA, 2005, p. 102) "Uma perspectiva crítica de currículo buscaria lidar com a questão da diferença como uma questão histórica e política. Não se trata simplesmente de celebrar a diferença e a diversidade, mas de questioná-la". Buscar mudanças das relações culturais repletas de mecanismos de poder, constituindo hierarquias e marcando preconceitos e discriminação a determinados grupos, é um desafio que encontramos na educação do século XXI. O que se propõe é uma educação para o reconhecimento do "outro", para o diálogo entre os diferentes grupos sociais e culturais.

Reflete Macedo (2010, p. 32): 
Desconstruir aqui significa, portanto, mostrar o quanto elas são arbitrárias, o quanto são, como são e porque foram construídas deliberadamente assim. Trata-se de libertar a cultura dos sentidos únicos que lhe foram sendo imputados como formas de manutenção do poder. Contingentes e mutáveis são os adjetivos que precisam ser acrescentados às fixações.

O processo desconstrutivo não é simples, já que temos que começar a desestabilizar a nós mesmos e colocar em xeque nossas crenças, estas que foram construídas na e pela cultura e influenciam o que assumimos como objeto de valor, formando nossa identidade. A educação nesse contexto desconstrutivo terá que desestruturar o que é assumido como conhecimento digno de fazer parte da grade curricular e o que não é.

Compreende-se assim que a instituição escolar pode não só contribuir com a reprodução de estruturas desiguais, sancionando de forma dissimulada e sutil as exclusões sociais, como também pode atuar buscando resistência e mudança, intervindo de forma crítica e com consciência política, levando os agentes em processo de aprendizagens escolares, a refletir sobre as construções históricas que, com a falsa ideia de arbitrárias, são na verdade o fruto de uma manutenção de status que privilegiam uns em relação a outros.

Segundo Furlani (2011, p. 59) "Se as identidades sociais são produzidas nas práticas culturais, e essa produção se dá nos processos de produção da diferença, então os significados, sejam eles quais forem podem ser contestados, negociados e transformados"

A escola pode ser locus propício para desconstruir fixações excludentes, segregarias e opressoras, em nome de uma falsa ordem natural de arranjos sociais, porém é necessário que analisar sob o crivo crítico sobre o que tal instituição tem transmitido, suas razões para a seleção de tal conteúdo e qual o público para quem esse é transmitido. Cabe também questionar sobre a concepção que se tem dos agentes sociais aprendizes: esses sujeitos são vistos como capazes de compreensão, reflexão e crítica?

A instituição escolar, dentre outras coisas, precisa rever seus currículos e as metodologias postas em prática, de forma a se identificar e desconstruir o que é assumido como processos de composição e perpetuação do que se assume estabelecido e naturalizado e do que é considerado diferente. 
Goellner (2010, p. 82) aponta "Por fim, qualquer prática pedagógica se faz por meio da intervenção de pessoas concretas, cujas ideias podem tanto reforçar as exclusões, os preconceitos, as violências, quanto minimizá-las". Os agentes participantes do processo de ensino e aprendizagem podem ter um grande potencial transformador desde que estes compreendam as amarras sociais presentes nos conteúdos incorporados na escola e também os conhecimentos relacionais desenrolados neste contexto. É preciso desestruturar a ideia de que determinados conteúdos são ensinados por força do hábito e reflitir sobre o que está por trás desses conteúdos. Os mecanismos de poder precisam ser identificados, problematizados e por que não superados.

\section{REFERÊNCIAS}

APPLE, M. W. Repensando ideologia e currículo. In: MOREIRA A. F.; SILVA, T. T. (ORG). Currículo, cultura e sociedade. São Paulo: Cortez, 1995. p 39-58.

APPLE, M. W. A política do conhecimento oficial: faz sentido a idéia de um currículo nacional?. In: APPLE, M. W. Política cultural e educação. São Paulo: Cortez, 2001. p. 53-78.

CANDAU, V. M. Multiculturalismo e educação: desafios para a prática pedagógica. CANDAU, V. M.; MOREIRA, F. M. (ORG). Multiculturalismo: diferenças culturais e práticas pedagógicas. Petrópolis, RJ: Vozes, 2008. p. 13-66.

CALLAI, C.; SERPA, A. Avaliação no cotidiano escolar. Currículo sem Fronteiras, v. 12, n. 2, p. 393-402, 2012.

FREITAS, L. C. A internalização da Exclusão. Educação \& Sociedade, v. 23, n. 80, p. 299-325, 2002.

FURLANI, J. Educação Sexual na sala de aula: relações de gênero, orientação sexual e igualdade étnico-racial numa proposta de respeito às diferenças. Belo Horizonte: Autêntica Editora, 2011.

GOELLNER, S. V. A educação dos corpos, dos gêneros e das sexualidades e o reconhecimento da diversidade. Cadernos de Formação RBCE, v. 1,n. 2, p. 71-83, 2010 .

LOURO, G. L. Gênero, sexualidade e educação: uma perspectiva pós-estruturalista. 2 ed. Petrópolis, RJ: Vozes, 1997.

MACEDO, E. A Cultura e a Escola. In: MISKOLCI, R. (ORG). Marcas da diferença no ensino escolar. São Carlos, SP: EdUFSCar, 2010. p. 11-44.

MCLAREN, P. Multiculturalismo Crítico (Trad. Bebel Orofino Schaefer). São Paulo: Cortez, 1997. 
NOGUEIRA, M. A.; NOGUEIRA, C. Um arbitrário cultural dominante. Revista Educação: Bourdieu Pensa a Educação, p. 36-45, 2010.

SACRISTÁN, J. G. O que significa o currículo?. In: SACRISTÁN, J. G. Saberes e Incertezas Sobre o Currículo. Porto Alegre: Penso, 2013. p. 16-35.

\section{Como referenciar este artigo}

LUCIFORA, Cristiane de Assis.; REINA, Fábio Tadeu. Currículo e questões de gênero uma relação de poder em meio escolar. Revista Temas em Educação e Saúde, Araraquara, v.14, n.1, p. 5-15, jan./jun., 2018. E-ISSN: 2526-3471. DOI: 10.26673/rtes.v14.n1.2018.9606

Submetido em: 26/03/2017

Aprovado em: 04/07/2017 